\title{
Erratum to: Chemometric study on the trace metal accumulation in the sediments of the Cochin Estuary-Southwest coast of India
}

\author{
P. M. Deepulal • T. R. Gireesh kumar • \\ C. H. Sujatha $\cdot$ Rejomon George
}

Published online: 30 December 2011

(C) Springer Science+Business Media B.V. 2011

\section{Erratum to: Environ Monit Assess \\ DOI 10.1007/s10661-011-2418-7}

The original version of this article unfortunately contained an error. Figure 2 has incorrect format.

Please see below for the correct format of Fig. 2.

The online version of the original article can be found at http:// dx.doi.org/10.1007/s10661-011-2418-7.

P. M. Deepulal $(\varangle) \cdot$ T. R. G. kumar • C. H. Sujatha

R. George

Department of Chemical Oceanography,

School of Marine Sciences, CUSAT,

Kochi 682516, India

e-mail: dlpmchem@gmail.com 
Fig. 2 Dendrogram showing station groups formed by group averaging cluster analysis of elemental concentration during three seasons
Pre-monsoon ( square deuclicain distance) Rescaled Distance Cluser Combine 10

stations

\begin{tabular}{cccccc} 
& \multicolumn{4}{c}{ Rescaled Distance Cluster Combine } \\
0 & 5 & 10 & 15 & 20 & 25
\end{tabular}

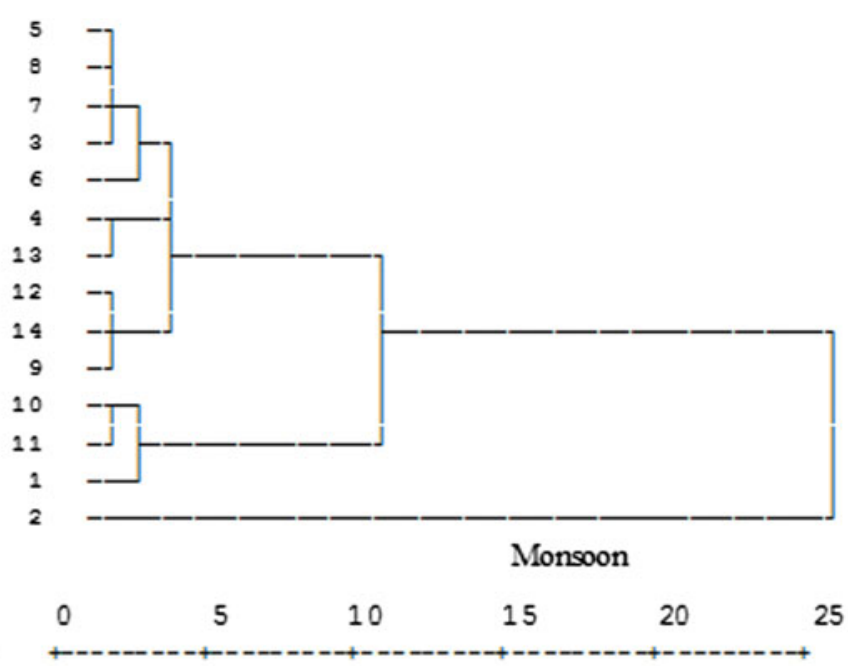

stations

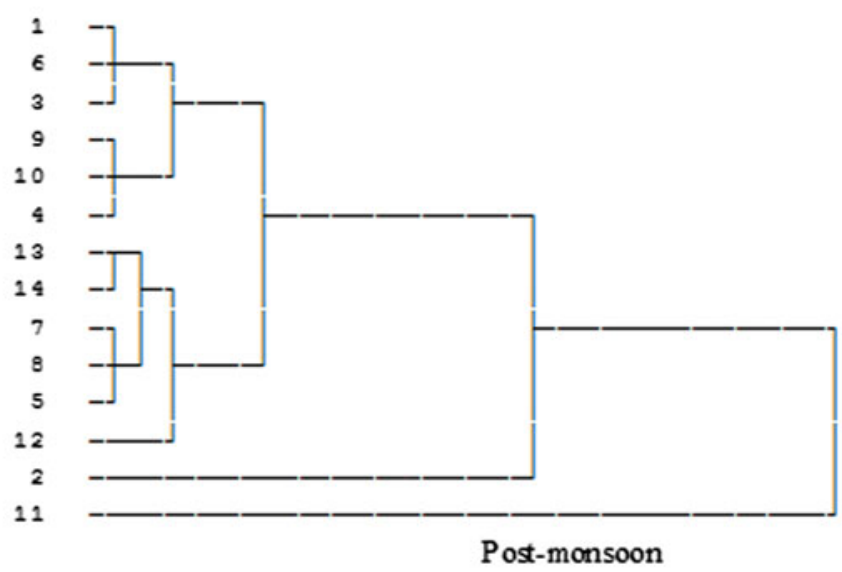

$\begin{array}{ccccccc} & 0 & 5 & 10 & 15 & 20 & 25 \\ \text { stations } & +- & 5 & 15 & \end{array}$

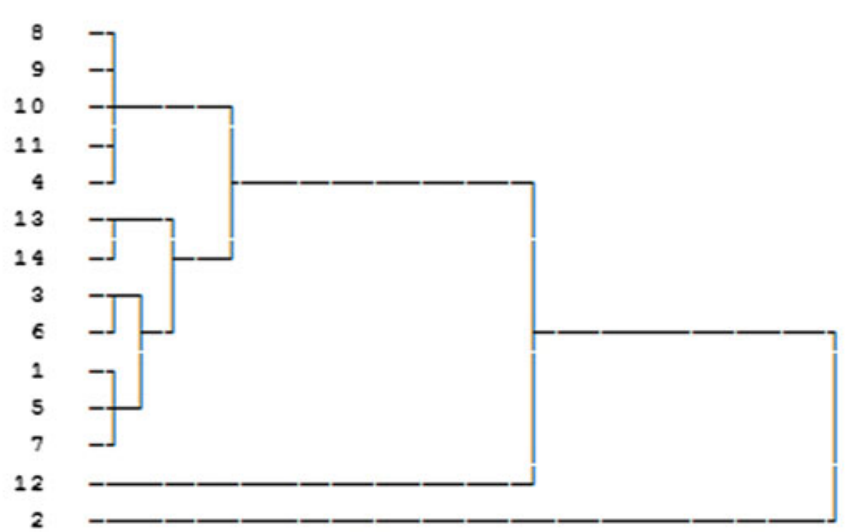

